\title{
A Manufacturing Business Process Reengineering Method: Design and Redesign of a Production Control Model
}

\author{
J. O. Strandhagen, Dr.ing.
}

T. Skarlo, Research Engineer

SINTEF Production Engineering, $N$ - 7034 Trondheim, Norway

Telephone: $+4773593138 \cdot$, Telefax: +4773597117

e-mail: ola.strandhagen@protek.unit.no,terje.skarlo@protek.unit.no

\begin{abstract}
Design and Redesign of a Production Control Model are methods for business process reengineering of manufacturing companies. It is a practical approach to assist companies that want to make the way they control their manufacturing processes a competitive advantage in meeting future market and customer demands. It is based on application of a mixture of techniques and methods from well known control principles. It has been developed and tested in a dozen Norwegian companies.
\end{abstract}

\section{Keywords}

Business Process Reengineering, Production Planning and Control, Material Flow, Layout, Production Control Model.

\section{INTRODUCTION}

In order to compete successfully, firms must achieve excellence in managing their manufacturing operations. Companies need to change the role of manufacturing from being "internal neutral" to "externally supportive" based on Hayes and Wheelwrights (1985) stages.

Several studies on performance have been performed. The best known is probably "Made in America" (Dertouzos, et. al, 1989) which studied how the US industry should change in order to regain competitiveness over Europe and Japan. A stronger focus on manufacturing was one of the major findings. In the Norwegian TOPP project a study of the performance of 50 Norwegian industrial companies was performed. This study showed that product development, quality management, production control, procurement and internal material flow all had a higher relative importance than performance, Bredrup et. al (1994). From Bredrup (1994), we also know that traditional accounting and performance measurement systems are not adequate to measure customer satisfaction. Neither has the focus on ISO 9000 seemed to improve the performance of those companies being certified by it. Many ISO certified companies experience less flexibility in adapting to new customer demands. There is also a clear new focus on the total value chain view, introduced by Porter (1985), which requires a new way of thinking when designing manufacturing systems. 
The new and current situation has not been coherent with the manufacturing and administrative processes of today's companies. There has been a need to develop methods and tools to redesign or re engineer the business processes of manufacturing companies. The traditional methods of redesigning the production system have been one of three; Either to choose and apply one of the "new" production control principles like Just in Time, OPT, or one of the more traditional ones. Or to directly copy solutions from other companies. Or the most misused one; to introduce (or even to change) an Electronic Data Processing system (most often based on MRPII) to "solve all problems". At NTH/SINTEF Production Engineering we have been working with these issues in several national as well as international projects. Through these projects, we have developed a practical method "Design of a Production Control Model" for manufacturing business process redesign.

\section{DESIGN OF A PRODUCTION CONTROL MODEL}

The basic idea of designing a Production Control Model is to make the way you organise and control your production and logistic system a competitive advantage for the company. It is a fact that products have shorter and shorter life cycles. The customers ask for specific designs with extremely short delivery times. The competition is global, making the price margins smaller. The first examples of requirements of $100 \%$ recyclable products are seen.

This challenge can be met by a redesign of the manufacturing business processes by developing a Production Control Model (PCM) based on;

- A vision of the future market (pull)

- An analysis of the existing system

the production system

the product characteristics

- Knowledge and experience of existing theories, methods and techniques

When the scenarios of the future market are defined, the challenge is then in a systematic, but yet creative, way to analyse the current situation, identify potentials and limitations, synthesise the solution into a model, and implement it.

The different topics to consider when analysing the existing system are the following processes and aspects;

- Production planning and control

- Inbound and outbound logistics

- Layout

- Capacity adjustment principles

- Product design aspects related

- Material flows

- Organisation

- Monitoring functions

- Performance measurement

A proposed definition of a Production Control Model is;

A Production Control Model is a description of how a production and logistic system is organised and controlled. It contains information about layout and material flows. It is used in redesign of a manufacturing system, as an operative control document, and for training purposes. The model defines a set of customer focused measurements to be used in the company.

The term model is used in the meaning as a description of a real world system, used to communicate and explain how the system should be organised and controlled. The following figure illustrates the process for redesign of a Production Control Model. The process is 
outlined as three streams, one for analysis and synthesis, one for education and training, and one for management discussions and decisions. The following sections will describe the analysis and synthesis in detail.

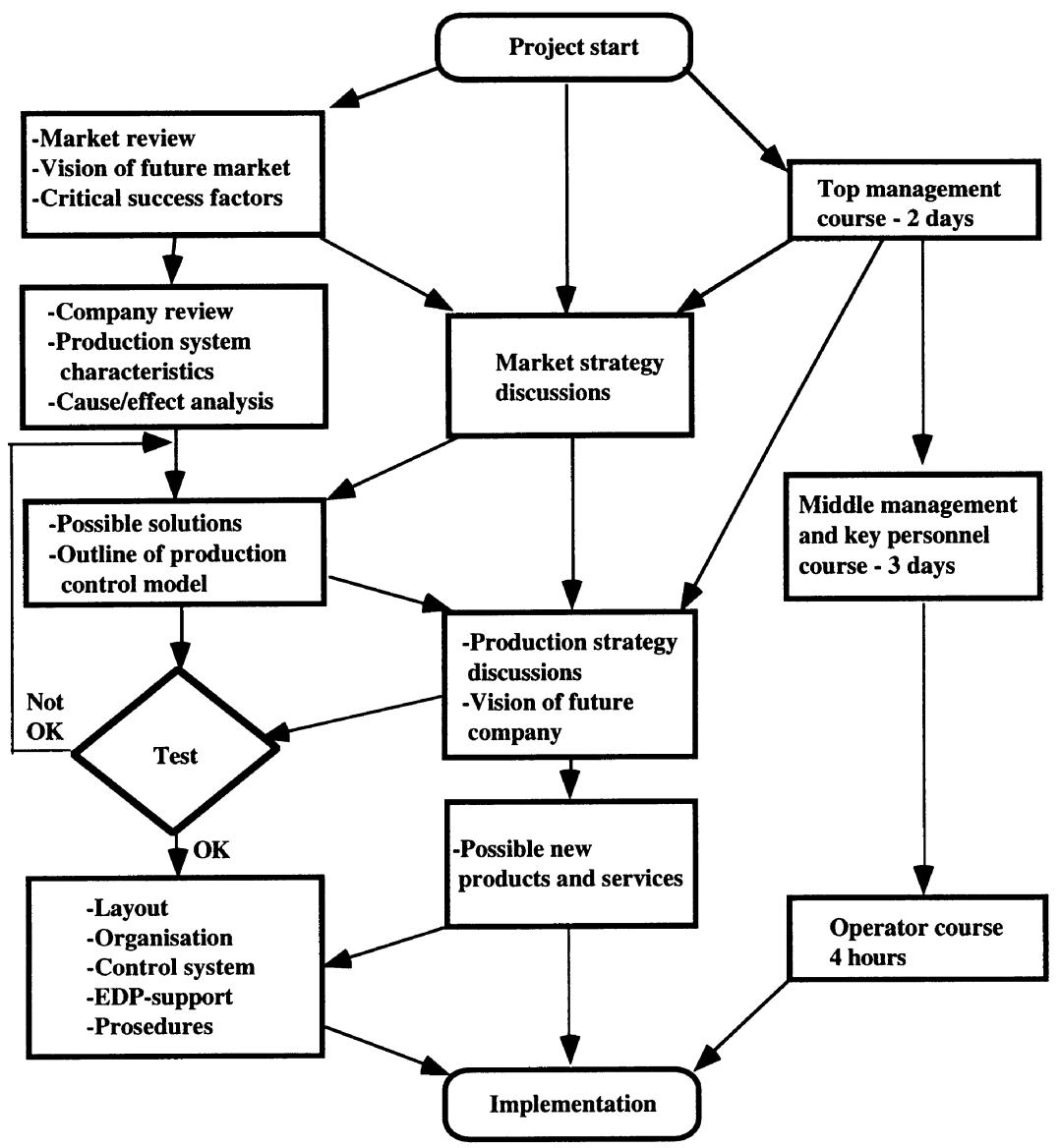

Figure 1 The process of design of a Production Control Model.

\section{THE ANALYSIS PHASE}

The analysis phase can be characterised by three main activities; data collection \& investigation, establish visions for the future company, and define performance measurements. It is of course important to aim for a systematic approach. The objective of the activity is to ensure understanding of the basic features of what is to be controlled. If the collection of data becomes too much oriented towards a specific solution, there is a tendency to concentrate on the first solutions that came up. Other possibilities may thus be left 
unexplored. Therefore a structure that is independent of the solutions, is applied. In short words, the following stepwise approach is recommended. Each of these steps are explained in the next sections;

- Identify what is important to achieve in the market - the visions of the future

- Collect data and analyse the current situation in the company

- Identify the characteristics of the production system

- Use cause/effect analysis

- Perform training and education of key personnel

- Define performance measurement system

\subsection{What is important to achieve in the market?}

The whole idea of a business process redesign is to improve competitiveness. It is therefore necessary to investigate how the future income can be increased by better performance on delivery terms. It is not sufficient to ask the market department what is important. One must also look at the development in other countries, within other business sectors and from the customer's point of view. It is important to have both a dynamic and a strategic perspective of the market development. Early achievements give a competitive advantage. However, it is difficult to give credible estimates on how much these improvements will be worth, and which competitors will achieve the same. The gain obtained by possible improvements may be short lived. The companies will always have to endeavour to search for new areas of possible improvements. At least the following future requirements must be identified;

- The expected delivery times

- New functionality and designs

- Future product variety
- The expected accuracy of deliveries

- The degree of customisation

- Price potentials of better performance

Common for all these items is that the development of them will influence directly on the production system.

\subsection{Collect and analyse data about the current situation in the company}

The most resource demanding activity in this first phase is probably the collection of data and information to describe the current situation in the company, and how the company performs today. This means how the market recognises the company's services, the efficiency of the production system, and how well prepared the company is to meet future challenges. The following areas are examined and evaluated;

- The company's services to the market

- Material flow and layout

- Tied-up capital regarding production

- Reliability of the production system

- Existence of unfavourable policy, culture, etc.
- Product design

- Production flexibility

- Inbound and outbound logistics

- Outline of the current PCM

Concerning the service to market, the following items are examined; delivery times, delivery performance, the ability to customise solutions, the quality of finished products, the market shares and the price level. On the other hand it is also important to find out how the market recognises the company's services, how much the company is paid for their services offered, and how the market recognises the most important competitors.

Another important aspect is the design of the products, as this is one of the two most important factors deciding on which control principles that can be applied (the production 
resources regarding flexibility and capability being the other). The factors of design to consider are; modularity in design, whether new designs are based on existing components, whether new products fit within existing product groups, design for ease of processing, assembly, automation, repair and production control and whether production people involved in product design. This should establish how production requirements are taken care of in product design, and how designers and production people are co-operating. The ability to increase product variety within existing processes is strongly limited by how the design issues are highlighted.

Burbidge's (1979) material and production flow analysis is well known as a mean to analyse the flow through the production systems. Aspects of particular importance in addition to pure material flow aspects are; throughput time, set-up times, bottleneck resources, transport distances, size of batches, stock levels, changes in area of responsibilities, intervening priorities and unnecessary handling.

Due to increasing product diversity, short product life time and focus on delivery performance, production flexibility is examined. The study concerns both the production system's abilities to handle day to day requirements and happenings, and on ability to handle possible future requirements. This can be analysed by examining the ability to; produce a mix of jobs (short set-up times), to change to other products than today, to change routing when breakdowns occur, to operate profitably at different volumes and the possibility to expand the production capacity.

The capital tied up in machines and equipment, as well as inventories must be identified.

Supply and distribution are predecessor and successor to the production. Delivery performance depends on efficiency and reliability in the whole logistic chain. Items to be examined are; the number of suppliers and transporters, the stability in the number of suppliers and transporters, the need for inspection of goods received, the use of EDI, and limits and regulations to be followed.

A production system requires both reliability and flexibility. Flexibility to handle the unexpected, reliability to avoid the undesirable. Both actual reliability, preventive efforts and possible reliability improvements are important issues. Following items must be considered; the supplier's delivery performance, the machinery breakdowns, the reject rates, the need for safety stocks, and the use of quality assurance and maintenance programmes.

Unfavourable results forced by executive policy, company culture, misunderstood loyalty, etc., can be obstacles to improvements. Major findings have to be identified. Examples are overuse of costly machinery, major belief in large batches, high utilisation rate synonymous to high productivity.

The company is after all in business and has a more or less successful way of controlling its production. Development of a new PCM will benefit from knowledge and understanding of the existing one. This means examining the production control principles, the dispatching rules, the use of pull and push, use of forecasts, which control areas exist, whether scheduling functions are applied, the actual role of planning personnel and the degree of computer support.

All these questions must be asked and answered, and the findings taken down and presented to all people involved. The major findings of this study must be commonly accepted as the description of the company. 


\subsection{Identification of the key characteristics of the production system}

On the basis of this information, the next step is to identify the key characteristics of the production system and its surroundings. Questions to be asked are;

- Does the company sell products or production capacity ?

- Is there an even or uneven workload throughout the year?

- How many product types and variants of products ?

- What are the typical number of processing stages ?

- What is the degree of use of common components ?

- Is production mainly repetitive or not ?

- What are the typical customer orders size ?

- What are the typical delivery times offered ?

- What are the possibilities of parallel operations ?

- What are the real serial effects ?

- Are there any identified bottlenecks ?

- Is there a product dependency regarding production process ?

- What is the stability in the production system ?

- What is the degree of out sourcing ?

The answer to these questions will give the key characteristics of the company. It is these characteristics that will limit, as well as give alternative, solutions.

\subsection{Cause/effect analysis}

Disclosing possibilities of improvement and outlining of a PCM is just a part of the process. A number of problems has to be dealt with before the production system has become controllable. When solving a problem, one must aim at attacking the root causes and not the symptoms. An important part of the analyses is the use of cause/effect diagrams (Kume, 1985 ), and the involvement of operators in the problem solving process. The cause/effect diagram shows the connections and dependencies in the problem complex. In addition to giving a survey, it is used to choose hypotheses regarding causes. The hypotheses are checked out by data collection and data analysis. The cause/effect diagram shows both possible effect and limitations, for example in production control improvements.

\subsection{Training and education of key personnel}

The whole idea of the method is that the PCM is the company's own solution to their challenge. To be able to take part in creating the solution, a substantial amount of training must be performed. The training is a mixture of practical examples and theory, where explanations and solutions are supposed to pop up during the training seminars.

\subsection{Define performance measurement system}

It is a common finding in the projects we have performed that many of the performance indicators that are applied, are not related to customer satisfaction nor profitability. And they are not indicators that are used to evaluate and improve, but simply to measure. An important aspect in improving performance is to identify indicators that are directly related to customer satisfaction or the ability to satisfy customers. Delivery performance is an example of the first, flexibility being an example of the second. To evaluate the production system indicators that cover the production's ability to produce the right products, at the right time, at the right quality and with a minimum use of resources, must be identified. They must cover this ability 
both in the present time and in the future. The measurements will be different in different companies, and they must include indicators for;

- Delivery performance

- Flexibility

- Claims from customers
- Resource utilisation

- Work in progress

- Planning and scheduling performance

Some companies spend too much resources on uncritical productivity monitoring, other spend too little effort on measurements. Often there is a mismatch between the effort on monitoring and the use of the data from the measurement. It is important that the chosen indicators really give productivity indications. One must also be aware that if indicators of little importance are measured, the fact that they are measured gives them importance.

\section{SYNTHESIS}

The analysis phase should already have initiated some ideas of possible solutions. But now the highly iterative synthesis phase is where these and constantly new solutions are merged, discussed and revised. The activities are;

- Identify basic principles and solutions that are applicable

- Make rough outline of Production Control Model

- Test of solutions

- Merge and integrate solutions

- Make complete Production Control Model

\subsection{Identification of basic principles and solutions that are applicable}

The first activity is to identify a set of possible solutions. The list below should be considered as an example of a practical approach of applying some of the basic techniques of all those well known control principles;

- Identify and confirm T-points and customer order decoupling points, CODPs

- Find customisation potentials from standard components

- Make layout flow oriented

- Combine group technology and cyclic production

- Introduce capacity adjusted order point

- Split of production into standard and special products

- Apply simple level based control where applicable

- Identify control areas

- Define information flows

Identify and confirm T-points and customer order decoupling points, CODPs Identical components used in several products can be stocked at the level where it spreads. This stock point (T-point) allows very short delivery time, depending on sufficient size it will absorb demand variations and it will be suitable for level control. T-point requires frequently use of the product or part. The T-point may coincide with the customer order decoupling point, CODP. But often the CODP is at a later stage in the production process. Both the Tpoint and the CODP must be identified, as they are the most important factor for deciding on which control principles to be applied where. 


\section{Find customisation potentials from standard components}

An ideal solution in many contexts is to supply customised products composed by standard components. This means to produce standard components and mount on order. Production control at a T-point will often be order controlled consumption and level controlled supply.

\section{Make layout flow oriented}

A flow oriented layout improves strongly the controllability. The methods for analysing and redesigning the material flow are well described in Burbidge (1979).

\section{Combined group technology and cyclic production}

Products that can be processed in the same tool set-up or with the same machine adjustments can be processed in sequence. In this way positive effects by producing one-of-a-kind or small series are obtained. It is the product family that constitutes the series. By emphasising the right order, this serial effect might be increased. The solution is a cyclical production.

\section{Group 1}

Group 2

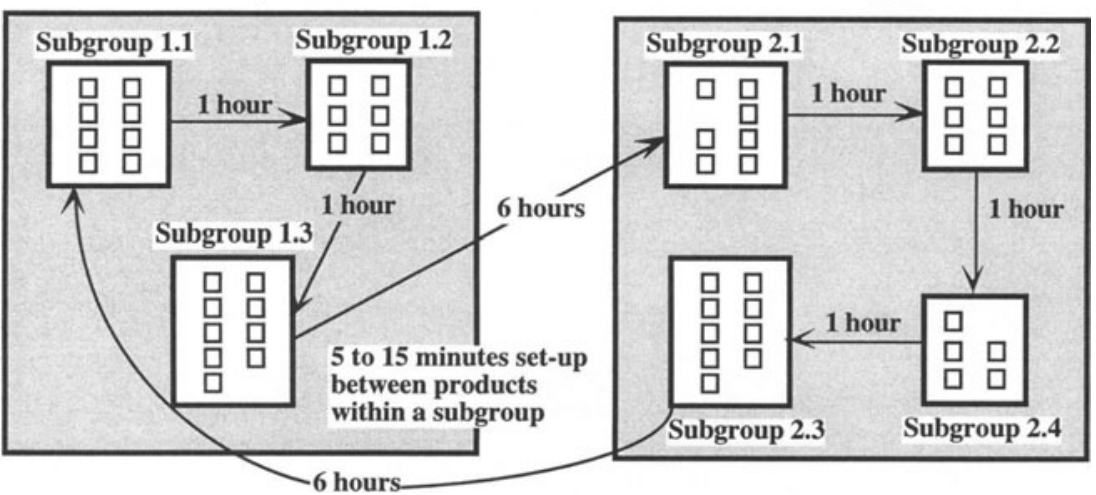

Figure 2 Group technology - Cyclical production.

\section{Introduce capacity adjusted order point}

A capacity adjusted order point takes into consideration the actual load on the production system. Possible production orders based on stock level or customer orders are grouped into must, should or may. A must order is critical with regard to delivery time and must be produced. A should order will soon become critical, or it is profitable to produce now due to favourable combinations with other products. It is up to the local manager or foreman to decide whether this order should be started or not. A may order is possible to start, but it should only be started if there are neither must nor should orders in the queue.

\section{Split of production into standard and special products}

Earlier the efficiency of a machine was solely measured by the number of processed units per hour. Lately more focus has been put on the flexibility of the machine. There still exist many high efficient machines with low flexibility (i.e. they are time-consuming to set up between the various products). In many companies there is an imbalance between the range of machines and the need for machines. A solution which has proven feasible in many companies is to separate the products into standard, processed in the old machine, and special. 
Thus the amount of special products will be so small that a flexible machine with a relatively low capacity may be sufficient.

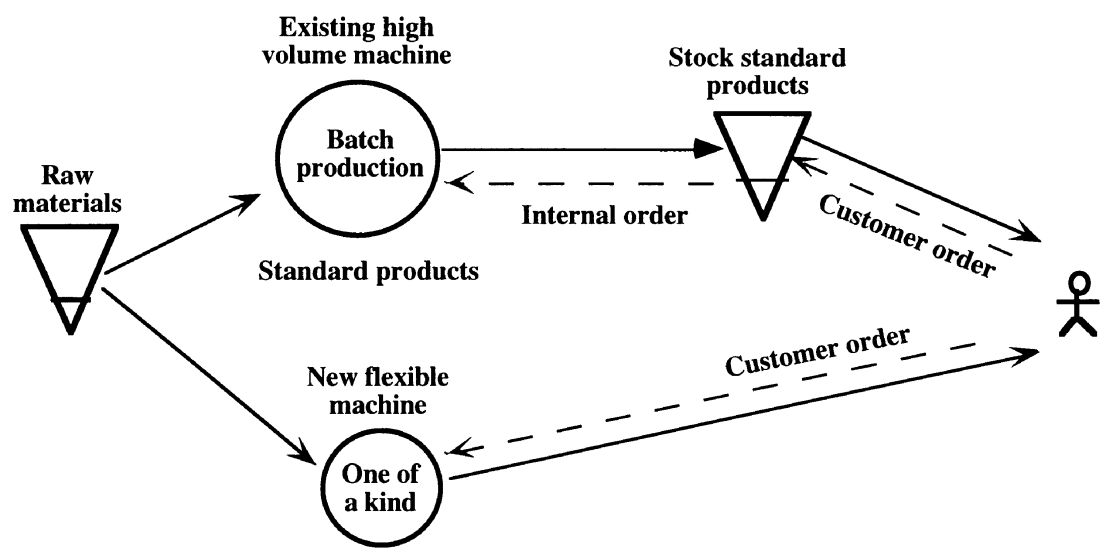

Special products

Figure 3 Split of standard and special production.

\section{Apply simple level based control where applicable}

As the use of MRPII systems, scheduling systems, bar codes and terminals has increased, the belief in using simple level based control techniques has decreased. Even for simple components advanced functions for calculating order sizes, printing production or purchasing orders, etc., has been implemented by use of computers. This has required a lot of administrative effort. We see now, probably as a result of the need for Just In Time performance, that many companies introduce KANBAN control principles. And that simple level based techniques like the Two-bin principle, have been reintroduced in many control systems. The basic idea is of course to use as little as possible effort and time on controlling standard components, and let these components be self-controlled by for instance KANBAN. And let the people and EDP systems concentrate on the complex, difficult to control customer designed components.

\section{Identify control areas}

Following the new layout, the identification of T-points and CODPs, and the control principles, new control areas must be defined. We know from several studies that the more often a production order crosses a border of responsibility, the more unnecessary delays occur. New control areas must be identified based on two major criteria. First, it is important that one manager/foreman has as few control principles as possible within his area. Secondly, the time required to perform the control tasks should be considered. These two criteria are much more important than for instance number of persons or machines, square meter, or number of product types.

\section{Define information flows}

The information flows are roughly defined by the control principles that are chosen. But it is important to exactly define the routes information flows, the responsible for these flows, and the routines to be followed. 


\subsection{Make rough outline of Production Control Model}

Based on the chosen principles, the new layout, the information flows and the specific solutions, a rough outline of PCM should be made. The model will indicate solutions, and is normally not more than a few pages of writing. An example of rough PCM is partly shown below. This example is a company producing furniture, and the rough PCM looks like this;

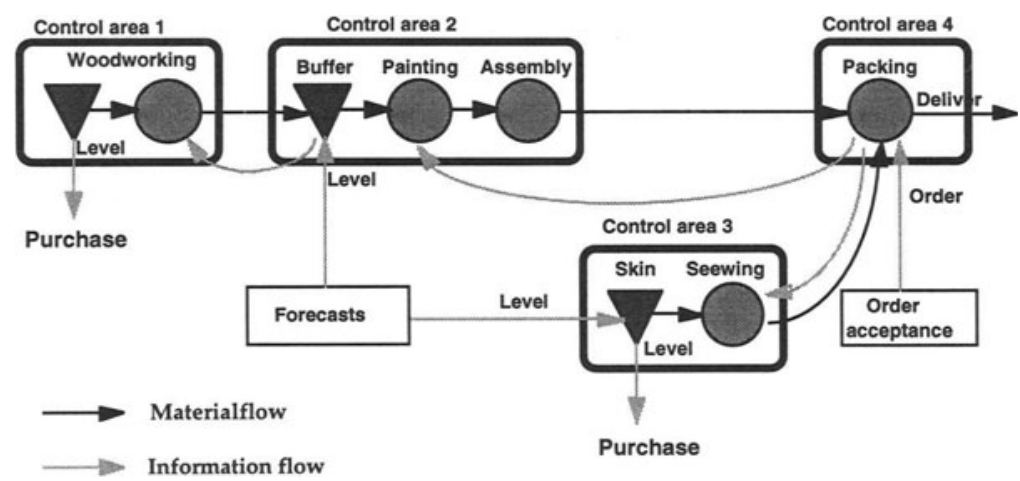

Figure 4 PCM for a Norwegian furniture company.

In addition to this figure, a list description of the control principles applied in each control area is defined. For the painting control area the following description is made;

\section{Control area 2; Painting}

Processes

Control of buffer of unpainted pieces, polishing, painting, spraying, assembly

Control

Receive orders on paper from Control area 4. Orders should be painted/sprayed and assembled within 8 working days. This area is free to mix jobs within these 8 days to minimise set-up cost of painting/spraying. The control points of the buffers are decided based on yearly forecasts. Extra capacity should be required from wood working, Control area 1.

Such descriptions are made for all areas, as well as a set of common rules for the whole production system.

\subsection{Test, merge and integrate solutions}

The next step is to find out if the proposed model will have the anticipated results. In simple cases the test can be carried out by using a spreadsheet and/or running a pilot implementation. When dealing with more complex cases, we recommend stochastic discrete event simulation. The objective of the test is to find out whether the proposed solutions works as expected, gives the expected production volume, whether the flexibility is sufficient for coping with the expected disturbances and what use of resources that have to be estimated. 
The next step is then to merge and integrate the solutions, identify discrepancies and correct them. New solution must be found. It is important that this is done with an open mind, as it is obvious that not all the initial solutions are feasible.

\subsection{Make complete Production Control Model}

The detailed and integrated solutions are included in complete Production Control Model. It is certainly not the final one, as it should be continuously changed as the surroundings and requirements change. The difference between the complete model is three things; It is far more detailed, the solutions are tested and integrated, and the use of EDP support is included. The model, still only existing on paper, must now be implemented.

\section{IMPLEMENTATION ADVICE}

A few remarks and some advice about the implementation process are needed. The emphasis on training and education is already mentioned. Another aspect is the need for topmanagement involvement. The whole idea is to make production control a competitive advantage in meeting future customer and market demands, making it a strategic issue.

The change-over process is critical. The change from old to new conditions has its own problems. It is of great importance to identify problem areas and to take preventive actions. These can include extraordinary limitations in delivery programme, full stocks, extra crew on expected bottlenecks, etc. There is a need for a specific plan to cover the change-over preparations and the change-over period. For some people every change is a fear. They struggle against all new. For others the new PCM entails that they lose importance and position. Some of them will struggle against too. It has to be taken into consideration that somebody will use implementation problems to prove they are right. The new PCM is not robust yet; small problems can grow big. Management has to ensure that positive and loyal people cover all positions of importance. The production capacity will possibly suffer during the change-over period. This possibility has to be co-ordinated with the sales department and even with customers. Build up of stocks and/or avoidance of sales campaigns just in this critical period can reduce risk for delivery problems.

\section{SUMMARY DISCUSSIONS}

This method has been applied with success in more than a dozen Norwegian manufacturing companies. They have all experienced radical improvements in performance. Examples of this will be presented at the conference, as well as in separate papers to be published. A major criticism to the method is that it is still very dependent on consultant's assistance. At NTH/SINTEF we have developed handbooks to assist the method, but up to now no companies have applied it without assistance.

The method should also be developed further with supporting methods for identification of problems and creating solutions. One example is the identification of area for KANBAN introduction, as well as maintenance of KANBAN systems. Another future area is integrating modelling tools, from traditional SADT diagrams to the enterprise modelling techniques, in the method. 


\section{ACKNOWLEDGEMENTS}

This method has been developed over more than 10 years, based on the experience gathered in a series of industrial projects, as well as projects financed by the Norwegian Research Council. We want to express our gratitude to all these companies as well as the Research Council. Special thanks to the companies Håg a.s and Dynoplast A.S Stjørdal who have been extremely co-operative in our joint projects. The term Production Control Model was introduced by our former colleague Tom Quistgaard, and we would also like to mention the important influence from the works and books of Professor Asbjørn Rolstadås and Professor John Burbidge.

\section{BIBLIOGRAPHY}

Jan Ola Strandhagen and Terje Skarlo are both working at NTH/SINTEF Production Engineering in the area of Production Management. Skarlo has a background from offshore engineering and construction companies, and has been a researcher at SINTEF since 1988. Strandhagen, with i dr.ing. degree from 1994, has been with SINTEF for ten years. He is Research Manager of the section for Production Management since 1992.

\section{REFERENCES}

Bredrup, H., Bredrup, R. and Rolstadås, A. (1994) PMS contribution to improved enterprise productivity. Proceedings from IFIP WG5.7 working conference on evaluation of production management methods, Porto Alegre/Gramado, Brazil.

Bredrup, H. (1994) Measurement systems based on standard costing inhibit JIT implementation. Proceedings from eighth international working seminar on productions economics, IGLS/Innsbruck, Austria.

Bredrup, H. (1994) Standard illusions: ISO 9000 as an alibi for quality. European Quality, $1(5)$.

Browne, J., Harhen, J., Shivnan, J. (1993) Production Management Systems - A CIM Perspective. Addison-Wesley Publishing Company.

Burbidge, J.L. (1979) Group technology in the engineering industry . Mechanical engineering publications Ltd., London.

Dertouzos, M.L., Lester, R.K., Solow, R.M. and The MIT Commission on Industrial Productivity. (1989) Made in America: Regaining the productive edge. The MIT Press, Cambridge, Massachusetts.

Hayes, R.H. and Wheelwright, S. C. (1985) Restoring our Competitive Edge: Competing through Manufacturing, John Wiley \& Sons, Boston, Mass.

Goldratt, M. and Cox, J. (1984) The Goal: Excellence in manufacturing. North River Press, Croton-on-Hudson.

Kume, H. (1985) Statistical methods for quality improvement. AOTS Chosakai, Ltd., Tokyo.

Porter, M.E. (1985) Competitive advantage: Creating and sustaining superior performance. Free Press, New York, N.J.

Rolstadås, A. (1995) Performance management - A business process benchmarking approach. Chapman \& Hall, London.

Shingo, S. (1985) A revolution in manufacturing: The SMED system. Productivity Press, Massachusetts and Connecticut. 